\title{
An experimental study on natural weathering of radionuclides from urban surfaces for aerosols deposited in wet and dry conditions
}

\author{
J. Brown, L. Ewers and M. Youngman \\ Centre for Radiation, Chemical and Environmental Hazards, Public Health England, Chilton, Didcot OX11 0RQ, UK.
}

\begin{abstract}
The European Model for Inhabited Areas (ERMIN) predicts long-term doses and other consequences following contamination of built-up areas by airborne radioactivity. Central to ERMIN are empirical models of the longterm behaviour of radionuclides on building and other surfaces in the environment. Experiments in which building materials were contaminated, and weathered outdoors for up to 1 year following contamination have enhanced the data on weathering from surfaces that can be used in ERMIN. New data have been obtained for the elements americium, cadmium, caesium, cobalt, iodine, ruthenium and strontium and for the surfaces brick, concrete and clay roof tiles, concrete slabs, glass, sandstone, tarmac and wood cladding. The results have highlighted some differences between the retention of aerosols on surfaces, particularly for glass. This paper presents a summary of the results and identifies the main differences in retention observed.
\end{abstract}

Keywords: remediation / decision support / surface retention

\section{Introduction}

The European Model for Inhabited Areas (ERMIN) predicts long-term doses and other consequences following contamination of built-up areas by airborne radioactivity. Central to ERMIN are empirical models of the long-term behaviour of radionuclides on building and other surfaces in the environment (Charnock, 2016). The weathering information currently used in ERMIN is largely based on caesium. Experiments in which building materials were contaminated and weathered outdoors for up to 1 year following contamination have been undertaken. The main aim was to look at how appropriate the data in ERMIN are for a range of surfaces and elements and to expand the pool of information available.

\section{Experimental design}

Building materials were contaminated with a range of radionuclides that represent groups of elements with different chemical properties that might be encountered following a radiological incident. The radionuclides chosen had gammaray emissions so they could be measured quickly by gamma spectrometry, enabling more experiments and repeated measurements to be made. Two parallel experiments were carried out: one set of surfaces contaminated using a simulated wet deposition and the other using a simulated dry deposition. PHE has the capability to generate droplets of solution containing soluble salts labelled with radionuclides. These were left to dry and deposit on the surface giving a simulated dry deposition. It is noted that starting with a solution and allowing the droplets to dry on the surface implies a high degree of solubility. Wet deposition was simulated by adding a solution containing the radionuclide to the surface and allowing it to dry.

The run-off water from each surface was regularly collected until any further removal was not measurable. The percentage removal of the contaminants was calculated from the amount of contaminant in the run-off water as a percentage of the initial amount of contaminant applied, having been decay corrected. A rainfall gauge measured the amount of rainfall in each measurement period. Results from earlier PHE work (Brown et al., 2011) have been added to the pool of data available to the PREPARE project. The experiments are summarised in Table 1.

\section{Results and discussion of retention on surfaces}

The results of PREPARE study are shown in Table 2. The main findings and observations from the experimental work are briefly described. Retention on porous surfaces (bricks, tiles, concrete and stone) was, in general, similar with a maximum removal of $50 \%$ and typical removals of $20-30 \%$ for 500-600 mm rainfall. An exception to this was observed for strontium, which was removed more quickly as well as all the contamination being removed (see Figure 1). This suggests that strontium remains more soluble in the surface matrix and is easily removed by rainfall.

There is limited evidence that dry deposition was removed somewhat quicker than wet deposition, and the total removed quantity over the experimental period (total of 527-mm 
Table 1. Summary of main weathering experiments in the two studies.

\begin{tabular}{llll}
\hline Element & Surfaces & Deposition & Duration/total rainfall \\
\hline PREPARE study & & & \\
Caesium, iodine, ruthenium & $\begin{array}{l}\text { Framed glass, brick, clay roof tile, sandstone, } \\
\text { tarmac, wood cladding }\end{array}$ & Wet, dry & 1 year (Sep-Sep)/629 mm \\
PHE study & Glass, brick, concrete roof tile, concrete slab & Wet & 5 months (Nov-Apr)/527 mm \\
Americium, cobalt, cadmium, strontium & & &
\end{tabular}

Table 2. Percentage of elements remaining on surfaces as a function of rainfall.

\begin{tabular}{|c|c|c|c|c|c|c|c|c|c|c|c|c|}
\hline \multirow[t]{2}{*}{ Date } & \multicolumn{4}{|c|}{ Nov 2013} & \multicolumn{3}{|c|}{ Dec } & \multicolumn{2}{|c|}{ Jan 2014} & \multirow{2}{*}{$\begin{array}{c}\text { Feb } \\
06 \\
\end{array}$} & \multirow{2}{*}{$\begin{array}{c}\text { Mar } \\
12\end{array}$} & \multirow{2}{*}{$\begin{array}{l}\text { Apr } \\
26\end{array}$} \\
\hline & 07 & 11 & 19 & 28 & 17 & 23 & 27 & 04 & 18 & & & \\
\hline Cumulative rainfall (mm) & 5 & 15 & 18 & 22 & 40 & 86 & 130 & 198 & 259 & 390 & 468 & 527 \\
\hline \multicolumn{13}{|l|}{ Cs (wet deposition) } \\
\hline Wood & 15 & 13 & 12 & 12 & 11 & 10 & 10 & 9 & 9 & 8 & 8 & 7 \\
\hline Glass & 6 & 3 & 3 & 3 & 3 & 3 & 2 & 2 & 2 & 2 & 2 & 2 \\
\hline Sandstone & 100 & 99 & 99 & 99 & 99 & 98 & 97 & 96 & 95 & 94 & 94 & 94 \\
\hline Tiled roof & 97 & 96 & 96 & 96 & 94 & 93 & 92 & 90 & 89 & 86 & 85 & 83 \\
\hline Tarmac & 100 & 99 & 99 & 99 & 99 & 99 & 99 & 99 & 99 & 98 & 98 & 98 \\
\hline Brick wall & 100 & 100 & 100 & 100 & 99 & 97 & 95 & 93 & 92 & 90 & 88 & 88 \\
\hline
\end{tabular}

Cs (dry deposition)

\begin{tabular}{|c|c|c|c|c|c|c|c|c|c|c|c|c|}
\hline Wood & 13 & 11 & 11 & 11 & 9 & 8 & 8 & 8 & 7 & 7 & 6 & 5 \\
\hline Glass & 10 & 10 & 10 & 9 & 9 & 9 & 9 & 9 & 9 & 9 & 9 & 9 \\
\hline Sandstone & 97 & 95 & 94 & 94 & 93 & 90 & 88 & 85 & 83 & 81 & 79 & 78 \\
\hline Tiled roof & 77 & 72 & 69 & 67 & 62 & 56 & 51 & 46 & 44 & 37 & 34 & 31 \\
\hline Tarmac & 93 & 91 & 90 & 89 & 89 & 88 & 87 & 86 & 85 & 84 & 83 & 82 \\
\hline Brick wall & 97 & 97 & 96 & 96 & 94 & 88 & 86 & 82 & 79 & 75 & 73 & 73 \\
\hline \multicolumn{13}{|c|}{$R u$ (wet deposition) } \\
\hline Wood & 44 & 40 & 36 & 36 & 35 & 34 & 34 & 33 & 32 & 31 & 29 & 28 \\
\hline Glass & 82 & 81 & 80 & 80 & 79 & 78 & 77 & 75 & 74 & 73 & 72 & 71 \\
\hline Sandstone & 100 & 99 & 99 & 99 & 98 & 95 & 92 & 84 & 75 & 66 & 59 & 56 \\
\hline Tiled roof & 95 & 94 & 93 & 93 & 92 & 91 & 90 & 89 & 89 & 88 & 87 & 86 \\
\hline Tarmac & 96 & 95 & 95 & 94 & 94 & 94 & 94 & 94 & 93 & 93 & 93 & 92 \\
\hline Brick wall & 100 & 100 & 100 & 100 & 100 & 99 & 99 & 98 & 98 & 97 & 97 & 97 \\
\hline \multicolumn{13}{|c|}{$R u$ (dry deposition) } \\
\hline Wood & 53 & 51 & 49 & 49 & 44 & 42 & 41 & 38 & 35 & 31 & 25 & 22 \\
\hline Glass & 31 & 31 & 30 & 30 & 29 & 29 & 28 & 28 & 27 & 26 & 25 & 24 \\
\hline Sandstone & 94 & 92 & 90 & 90 & 88 & 84 & 82 & 78 & 76 & 72 & 69 & \\
\hline
\end{tabular}


Table 2. (continued).

\begin{tabular}{|c|c|c|c|c|c|c|c|c|c|c|c|c|}
\hline \multirow[t]{2}{*}{ Date } & \multicolumn{4}{|c|}{ Nov 2013} & \multicolumn{3}{|c|}{ Dec } & \multicolumn{2}{|c|}{ Jan 2014} & \multirow{2}{*}{$\begin{array}{c}\text { Feb } \\
06 \\
\end{array}$} & \multirow{2}{*}{$\begin{array}{l}\text { Mar } \\
12 \\
\end{array}$} & \multirow{2}{*}{$\begin{array}{r}\text { Apr } \\
26 \\
\end{array}$} \\
\hline & 07 & 11 & 19 & 28 & 17 & 23 & 27 & 04 & 18 & & & \\
\hline Tiled roof & 84 & 82 & 80 & 79 & 76 & 73 & 71 & 67 & 64 & 60 & 57 & 53 \\
\hline Tarmac & 73 & 69 & 64 & 63 & 59 & 56 & 53 & 50 & 47 & 43 & 36 & 32 \\
\hline Brick wall & 98 & 97 & 96 & 96 & 93 & 83 & 78 & 74 & 71 & 66 & 63 & 62 \\
\hline \multicolumn{13}{|c|}{ I (wet deposition) } \\
\hline Wood & 92 & 90 & 90 & 90 & 87 & 86 & 86 & 84 & 83 & 80 & 78 & 78 \\
\hline Glass & 95 & 95 & 95 & 95 & 95 & 95 & 95 & 95 & 95 & 95 & 95 & 95 \\
\hline Sandstone & 98 & 97 & 97 & 97 & 96 & 94 & 93 & 90 & 87 & 83 & 81 & 81 \\
\hline Tiled roof & 85 & 78 & 76 & 75 & 72 & 71 & 70 & 68 & 67 & 64 & 62 & 62 \\
\hline Tarmac & 95 & 91 & 90 & 89 & 87 & 86 & 86 & 85 & 83 & 82 & 80 & 79 \\
\hline Brick wall & 100 & 100 & 100 & 100 & 99 & 97 & 96 & 93 & 90 & 87 & 87 & 87 \\
\hline \multicolumn{13}{|c|}{ I (dry deposition) } \\
\hline Wood & 70 & 64 & 63 & 62 & 54 & 51 & 51 & 44 & 41 & 41 & 41 & 41 \\
\hline Glass & 90 & 90 & 90 & 90 & 90 & 90 & 90 & 90 & 90 & 90 & 90 & 90 \\
\hline Sandstone & 90 & 85 & 84 & 83 & 81 & 78 & 77 & 71 & 68 & 67 & 67 & 67 \\
\hline Tiled roof & 60 & 52 & 49 & 49 & 45 & 42 & 41 & 39 & 36 & 36 & 36 & 36 \\
\hline Tarmac & 60 & 43 & 38 & 36 & 30 & 29 & 29 & 23 & 20 & 19 & 19 & 19 \\
\hline Brick wall & 98 & 97 & 96 & 96 & 95 & 91 & 90 & 85 & 81 & 81 & 81 & 81 \\
\hline
\end{tabular}

Concrete roof tile - Building Materials, natural weathering

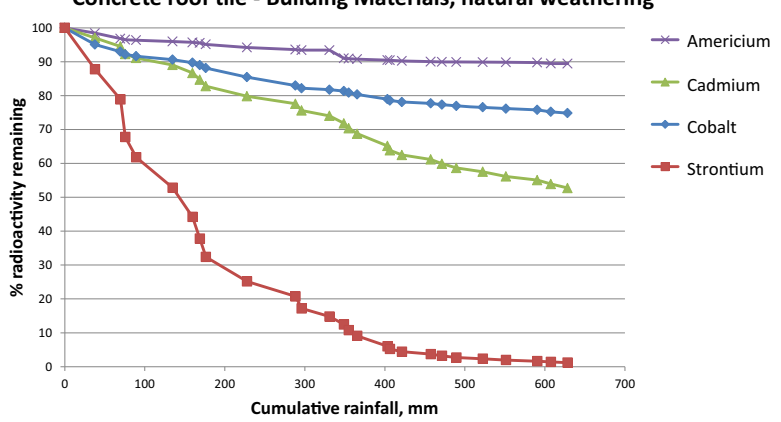

Figure 1. Weathering from concrete roof tile.

rainfall) was higher, although this was not consistent across the building materials. For clay roof tiles and tarmac, there was clearer evidence that the dry deposition, particularly of iodine and ruthenium, was higher by a factor of about 2-3 (60-70\% removed compared to $10-20 \%$ removed for wet deposition). Figure 2 shows a comparison of weathering following simulated wet and dry deposition for brick wall and tarmac that shows the differences.

For glass and wood cladding, an initial high removal at the time of the first rainfall was observed, except for americium. Further experiments indicated that the short-term removal of elements from glass, and particularly americium, was dependent both on the time between deposition and the first rain and the weather conditions over this period, hot weather appearing to effectively 'bake' the contamination onto the surface with the effect of significantly slowing down the rate of removal. There is some evidence that iodine and ruthenium were removed less from wood and glass than the other elements. The overall weathering from glass was also observed to be very variable and different between the PHE and PREPARE studies. A sheet of glass was used in the PREPARE experiments rather than glass in a window frame, the latter showing a much higher overall removal. It is difficult to further interpret these results, as the initial weather conditions, the amount of rain during the first rainfall event following deposition and possibly the type of glass; all appear to influence the amount and rate of weathering.

\section{Conclusion}

Undertaking experiments in real weather conditions has meant that interpretation of the results is not straightforward, as there are potentially many factors influencing the weathering removal and removal rate, as would be the case in reality. The overall rainfall in the 2 experimental periods was similar, although the rainfall pattern was different. The experiments show that, in general, there are not significant differences between the weathering of different elements 

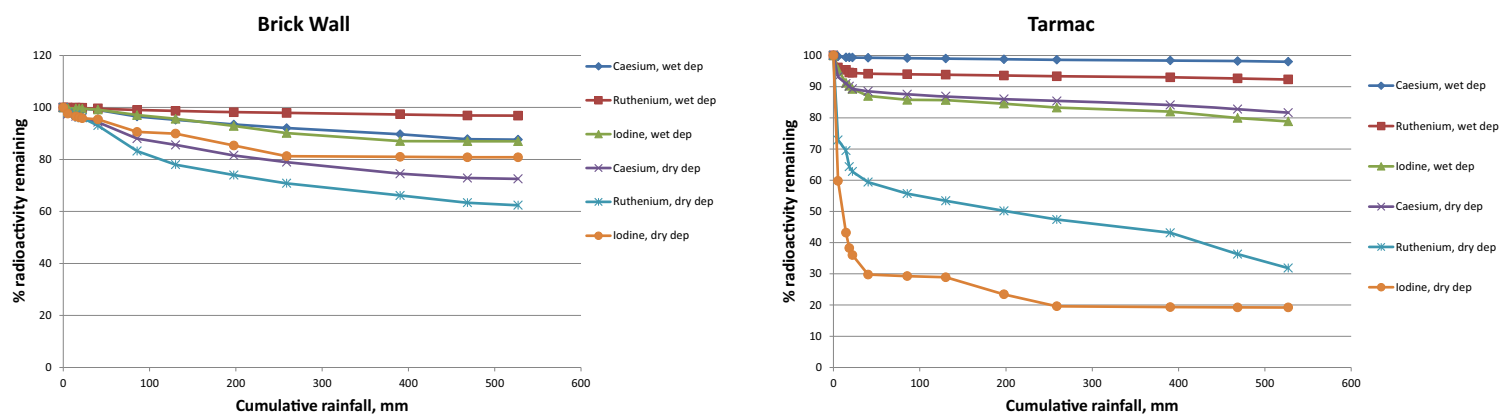

Figure 2. Weathering from brick wall and tarmac showing differences between elements.

from an individual surface with a few exceptions, notably strontium. There are differences, however, between surfaces, the notable one being glass, where removal is variable and not necessarily rapid, as might be expected. The results also indicate that there can be significant removal during the first rainfall event following deposition, and it may be appropriate to include this feature in the ERMIN model. The data will be used to derive weathering rates for aerosols for use in ERMIN.

Acknowledgement. The research leading to these results has received funding from the European Atomic Energy Community Seventh
Framework Programme FP7/2012-2013 under grant agreement 323287.

\section{References}

Brown J., et al. (2011) Development of experimental techniques to investigate the behaviour of chemical and radiological materials on urban surfaces. HPA Chemical Hazards and Poisons Report, Issue 20.

Charnock T.W. (2016) Enhancement of the ERMIN urban dose and remediation model to account for physicochemical properties of contamination, Radioprotection, 51 (HS2), S105-S107.

Cite this article as: J. Brown, L. Ewers, M. Youngman. An experimental study on natural weathering of radionuclides from urban surfaces for aerosols deposited in wet and dry conditions. Radioprotection 51(HS2), S109-S112 (2016). 